\title{
The Relationship between Mean Pulmonary Artery Pressure and Quality of Life in Patients with Mitral Stenosis
}

\author{
Ali Zorlu $^{a} \quad$ Gullu Amioglu $^{\mathrm{a}} \quad$ Nuryil Yilmaz $^{\mathrm{c}} \quad$ Murat Semiz $^{\mathrm{b}} \quad$ Meltem Refiker Ege $^{\mathrm{d}}$ \\ Gulay Aydina Izzet Tandogan ${ }^{a} \quad$ Mehmet Birhan Yilmaz ${ }^{a}$ \\ Departments of a Cardiology and ${ }^{b}$ Psychiatry, Cumhuriyet University School of Medicine, \\ ${ }^{\mathrm{c} P s y c h i a t r y}$ Clinic, Sivas State Hospital, Sivas, and ${ }^{\mathrm{d}}$ Cardiology Clinic, Yalova State Hospital, Yalova, Turkey
}

\section{Key Words}

Mitral stenosis - Quality of life - Mean pulmonary artery pressure $\cdot$ Echocardiography

\begin{abstract}
Objectives: We aimed to evaluate echocardiography-guided hemodynamic determinants of quality of life (QoL) via the Medical Outcomes Study Short Form (SF-36) questionnaire in patients with mild to moderate mitral stenosis (MS). Methods: Eighty consecutive patients with rheumatic MS, who were admitted to the outpatient department, were enrolled into the study upon obtaining informed consent. Forty agesex-matched healthy individuals were enrolled as a control group. Results: All subscale scores and total SF-36 scores were significantly lower in the patient group representing a worse QoL. In multivariable logistic regression analysis, only mean pulmonary artery pressure (OR 1.138, 95\% Cl 1.049$1.234, p=0.002$ ) was found to be an independent predictor of poor QoL in patients with mild to moderate MS. Conclusion: During follow-up of MS patients before intervention, physicians should consider that mean pulmonary artery pressure is the main factor which influences the patients' QoL. In patients with MS, it seems that referral to intervention should consider components and derivatives of QoL.
\end{abstract}

Copyright @ 2011 S. Karger AG, Basel

\section{Introduction}

Quality of life (QoL) is an integral part of health. On the other hand, valvular heart diseases are known to influence QoL. Although the incidence of acute rheumatic fever in industrialized countries has declined in the last 50 years as a result of improved socioeconomic conditions, mitral stenosis (MS) is still a frequent problem in developing countries, particularly in young women [1]. The natural history of rheumatic MS begins with an asymptomatic latent period, and has a mean interval of $16.3 \pm 5.2$ years between initial cardiac involvement and the appearance of symptoms secondary to MS [2]. However, once the symptoms appear, they bring about problems in QoL of this relatively younger population. Although recent studies have assessed the factors affecting QoL of patients following valvular surgery [3-5], limited data are available on the assessment of QoL in patients during the follow-up period before an intervention. Furthermore, gender differences in the QoL during the preoperative period are solely based on studies about coronary artery bypass surgery, since studies with valvular patients exclusively are lacking [6-8]. QoL via the Medical Outcomes Study Short Form (SF-36) questionnaire was previously assessed in patients following mitral valve surgery $[9,10]$. However, hemodynamic determinants of

\section{KARGER}

Fax +4161306 1234 E-Mail karger@karger.ch www.karger.com

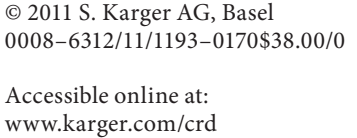

Ali Zorlu, MD

Cumhuriyet University School of Medicine

Department of Cardiology

TR-58140 Sivas (Turkey)

Tel. +90 346258 1800, E-Mail dralizorlu@gmail.com 
impaired QoL have not been evaluated before. Hence, in this study, we aimed to evaluate echocardiography-guided hemodynamic determinants of QoL via SF-36 questionnaire in patients with mild to moderate MS.

\section{Methods}

Eighty consecutive patients with mild to moderate rheumatic MS, who were referred to outpatient echocardiography departments of participating centers, were enrolled into the study upon qualifying for the study and obtaining informed consent. Forty age-sex-matched healthy individuals (from all participating centers) were enrolled as a control group. Echocardiographic evaluation was performed prospectively by expert echocardiographers via a defined protocol. Those with any other severe valve disease which dominates the clinical picture (that is, patients with severe aortic stenosis, severe aortic regurgitation, severe mitral regurgitation, severe tricuspid regurgitation), noncompliant patients, patients with MS secondary to annular calcification, patients with congenital MS, patients with recent history of rheumatic fever within the last 6 months, patients with depressed ejection fraction, and those with any kind of previous cardiac surgery as well as patients with recent exacerbation presumably secondary to valvular disease were excluded from the study. Besides, patients with planimetric valve area $<1 \mathrm{~cm}^{2}$ were not included in the study, since these patients were usually those who were referred with the intention to intervene MS, hence, we thought this could have influenced the perception of QoL. The protocol was approved by the institutional ethics committee as a thesis in profession and all participants gave informed written consent.

All patients underwent echocardiographic examinations with a cardiac ultrasound scanner (in all participating centers: Vivid 7; GE) and a $2.5-\mathrm{MHz}$ transducer in the left lateral decubitus position, with utilization of standard views and measurements by expert echocardiographers according to guidelines and recommendations for chamber quantification within a defined protocol [11]. A 12-lead electrocardiogram was simultaneously recorded for each patient. Resting heart rate during echocardiography was 55$85 /$ min in all patients. All echocardiograms were recorded by echocardiographers with codes without identities to eliminate interobserver variability. Recorded and coded data were put into random order by computer assistance and evaluated offline by an expert echocardiographer who did not know anything about the study. Patients with MS were determined on the basis of the following criteria: fibrotic thickening of the mitral valve, doming of the anterior mitral valve along with diminished $\mathrm{E}$ to $\mathrm{F}$ slope during diastole and upward movement of the posterior valve during early diastole [12]. Mitral valve area was determined by two-dimensional planimetry and if the image quality was not accurate enough for planimetry, Doppler pressure half-time was obtained [12]. Transmitral gradient including the mitral peak pressure gradient and mitral mean pressure gradient were calculated by the modified Bernoulli equation at rest [13]. The mitral valve Wilkins echocardiographic score was calculated for each patient between 4 and 16 [14]. Mitral, aortic and tricuspid regurgitations were quantified according to recent guidelines, and categorized as triv$\mathrm{ial} / \mathrm{mild} /$ moderate [11]. Systolic pulmonary artery pressure was derived from the tricuspid regurgitation jet velocity with modi- fied Bernoulli equation $\left(4 v^{2}\right)$ and estimating a right atrial pressure from inferior vena cava collapsibility [15]. Mean pulmonary artery pressure was calculated by the Masuyama method [16]. Tricuspid annulus velocities via tissue Doppler, right ventricular outflow time-velocity integral, ejection times, intervals and tricuspid annular plane systolic excursion were measured accordingly in all patients [17-19]. The average of at least five recorded measurements was considered as the final value of each parameter.

Laboratory tests were assessed in the blood samples obtained on the day of echocardiographic evaluation. Clinical parameters including accompanying diseases and medical treatment were considered in a standardized manner.

All patients underwent QoL assessment via the SF-36 questionnaire by experts who were blinded to echocardiographic data and, finally, evaluations were verified by a psychiatrist (N.Y.). SF36 is a self-administered health survey instrument that has been used to assess health-related QoL in cardiac surgery patients [20]. The questionnaire is composed of eight scales to measure health: physical functioning (I), role functioning - physical (II), bodily pain (III), general health (IV), vitality (V), social functioning (VI), role functioning - emotional (VII) and mental health (VIII). The responses to each of these questions were summed up and transformed to give eight scores between 0 and 100, with higher scores indicating a better state. The physical (PCS) and mental component summary (MCS) are gained by weighting and summing up of the original scales of the SF-36 [20].

\section{Statistical Analyses}

Parametric data were expressed as means \pm standard deviation and categorical data as percentages. SPSS 16.0 (SPSS. Inc., Chicago, Ill., USA) was used to perform statistical procedures. Independent parameters were compared via independent samples $\mathrm{t}$ test. The Mann-Whitney $\mathrm{U}$ test was used to test parametric data without binomial distribution. Categorical data were evaluated by $\chi^{2}$ test as appropriate. SF-36 score was classified into higher and lower (patient group) total SF-36 score according to median value. Factors having a significant association with poor QoL score (lower SF-36 score) were entered into multivariable logistic regression analysis with forward stepwise method. Receiver operator characteristic curve analysis was performed to identify the optimal cutoff point of mean pulmonary artery pressure (at which sensitivity and specificity would be maximal) for the prediction of poor QoL. Areas under the curve (AUC) were calculated as measures of the accuracy of the tests. We compared the AUC with use of the $\mathrm{Z}$ test. A p value $<0.05$ was accepted as significant.

\section{Results}

Mean age of the study group was $49 \pm 14$ years with a gender distribution of 14 males and 66 females, and was not different from the control group ( $48 \pm 4$ years, $\mathrm{p}=$ $0.539 ; 10$ males, 30 females, $p=0.468$ ). In the study group, mean planimetric valve area was $1.55 \pm 0.27 \mathrm{~cm}^{2}$, with mean transmitral gradient of $6.4 \pm 3 \mathrm{~mm} \mathrm{Hg}$, and with mean ejection fraction of $56 \pm 8 \%$. 
Table 1. The comparison of the patient group with the control group

\begin{tabular}{lccr}
\hline & $\begin{array}{l}\text { Patient } \\
\text { group } \\
(\mathrm{n}=80)\end{array}$ & $\begin{array}{l}\text { Control } \\
\text { group } \\
(\mathrm{n}=40)\end{array}$ & $\mathrm{p}$ \\
\hline Age, years & $49 \pm 14$ & $48 \pm 4$ & 0.539 \\
Gender, male/female & $14 / 66$ & $10 / 30$ & 0.468 \\
Physical function & $71.6 \pm 16.9$ & $88.6 \pm 5-8.3$ & $<0.001$ \\
Physical role function & $72.0 \pm 19.9$ & $86.2 \pm 7.7$ & $<0.001$ \\
Bodily pain & $63.1 \pm 19.6$ & $84.4 \pm 8.3$ & $<0.001$ \\
General health & $52.0 \pm 14.3$ & $90.6 \pm 3$ & $<0.001$ \\
Vitality & $58.1 \pm 16.2$ & $91 \pm 2.1$ & $<0.001$ \\
Social function & $73.0 \pm 22.7$ & $84 \pm 7$ & 0.001 \\
Emotional role function & $73.1 \pm 21.4$ & $85.4 \pm 9.5$ & 0.005 \\
Mental health & $64.2 \pm 16.3$ & $89.7 \pm 4.3$ & $<0.001$ \\
\hline PCS of SF-36 & $63.4 \pm 12.4$ & $88.1 \pm 3.1$ & $<0.001$ \\
MCS of SF-36 & $64.2 \pm 12.6$ & $87.4 \pm 2.8$ & $<0.001$ \\
\hline Total SF-36 score & $66.0 \pm 12.5$ & $87.3 \pm 2.9$ & $<0.001$ \\
\hline
\end{tabular}

Table 2. The comparison of the basic characteristics of patients with MS after classifying the patients into two subgroups according to median total SF-36 score

\begin{tabular}{|c|c|c|c|}
\hline & $\begin{array}{l}\text { Group } 1 \\
(\mathrm{n}=40) \\
(\text { total SF-36 } \\
\text { score }>65)\end{array}$ & $\begin{array}{l}\text { Group 2 } \\
(\mathrm{n}=40) \\
\text { (total SF-36 } \\
\text { score } \leq 65)\end{array}$ & $\mathrm{p}$ \\
\hline Mean age, years & $46 \pm 15$ & $52 \pm 13$ & 0.104 \\
\hline Female & $30(75 \%)$ & $36(90 \%)$ & 0.070 \\
\hline Height, cm & $161 \pm 8$ & $159 \pm 6$ & 0.341 \\
\hline Weight, kg & $69 \pm 11$ & $74 \pm 15$ & 0.071 \\
\hline $\mathrm{BSA}, \mathrm{m}^{2}$ & $1.7 \pm 0.1$ & $1.8 \pm 0.2$ & 0.185 \\
\hline BMI & $27 \pm 5$ & $29 \pm 6$ & 0.052 \\
\hline Presence of hypertension & $11(28 \%)$ & $22(55 \%)$ & 0.011 \\
\hline Duration of hypertension, years & $4 \pm 3$ & $6 \pm 8$ & 0.214 \\
\hline Presence of diabetes mellitus & $2(5 \%)$ & $7(18 \%)$ & 0.077 \\
\hline Duration of diabetes mellitus, years & $1 \pm 2$ & $4 \pm 10$ & 0.089 \\
\hline Hyperlipidemia & $8(20 \%)$ & $10(25 \%)$ & 0.395 \\
\hline Duration of hyperlipidemia, years & $2 \pm 2$ & $1 \pm 2$ & 0.508 \\
\hline Smoking & $8(20 \%)$ & $3(8 \%)$ & 0.096 \\
\hline Duration of smoking, years & $8 \pm 11$ & $3 \pm 11$ & 0.187 \\
\hline Atrial fibrillation & $13(33 \%)$ & $19(48 \%)$ & 0.127 \\
\hline Antiplatelet agents & $28(70 \%)$ & $27(68 \%)$ & 0.500 \\
\hline Beta blockers & $20(50 \%)$ & $27(68 \%)$ & 0.086 \\
\hline ACE inhibitors/ARB & $10(25 \%)$ & $17(43 \%)$ & 0.078 \\
\hline Statins & $30(75 \%)$ & $36(90 \%)$ & 0.070 \\
\hline Diuretics & $7(18 \%)$ & $11(28 \%)$ & 0.211 \\
\hline Calcium canal blockers & $7(18 \%)$ & $12(30 \%)$ & 0.147 \\
\hline Digitalis & $5(13 \%)$ & $8(20 \%)$ & 0.273 \\
\hline Coumadin & $14(35 \%)$ & $16(40 \%)$ & 0.409 \\
\hline
\end{tabular}

$\mathrm{ACE}=$ Angiotensin-converting enzyme; $\mathrm{ARB}=$ angiotensin receptor blocker; $\mathrm{BSA}$ = body surface area; $\mathrm{BMI}=$ body mass index.
Table 3. The comparison of the echocardiographic parameters of patients with MS after classifying the patients into two subgroups according to median total SF-36 score

\begin{tabular}{|c|c|c|c|}
\hline & $\begin{array}{l}\text { Group 1 } \\
(\mathrm{n}=40) \\
(\text { total SF-36 } \\
\text { score }>65)\end{array}$ & $\begin{array}{l}\text { Group 2 } \\
(\mathrm{n}=40) \\
\text { (total SF-36 } \\
\text { score } \leq 65)\end{array}$ & $\mathrm{p}$ \\
\hline E velocity, m/s & $1.4 \pm 0.6$ & $1.2 \pm 0.7$ & 0.435 \\
\hline A velocity, $\mathrm{m} / \mathrm{s}$ & $1.4 \pm 0.5$ & $1.5 \pm 0.4$ & 0.618 \\
\hline $\mathrm{E} / \mathrm{A}$ ratio & $0.9 \pm 0.4$ & $0.8 \pm 0.4$ & 0.210 \\
\hline Ejection fraction, \% & $56 \pm 7$ & $55 \pm 8$ & 0.712 \\
\hline LV diastolic volume, $\mathrm{ml}$ & $93 \pm 30$ & $93 \pm 22$ & 0.983 \\
\hline LV systolic volume, $\mathrm{ml}$ & $40 \pm 13$ & $41 \pm 14$ & 0.741 \\
\hline Left atrial diameter $4 \mathrm{C} 1, \mathrm{~cm}$ & $4.6 \pm 0.9$ & $4.8 \pm 0.8$ & 0.492 \\
\hline Left atrial diameter $4 \mathrm{C} 2, \mathrm{~cm}$ & $6.7 \pm 1.0$ & $6.8 \pm 1.1$ & 0.850 \\
\hline Area of left atrium, $\mathrm{cm}^{2}$ & $27 \pm 9$ & $35 \pm 50$ & 0.334 \\
\hline Right atrial diameter $4 \mathrm{C} 1, \mathrm{~cm}$ & $3.8 \pm 0.9$ & $3.9 \pm 0.7$ & 0.765 \\
\hline Right atrial diameter $4 \mathrm{C} 2, \mathrm{~cm}$ & $5.2 \pm 1.1$ & $5.4 \pm 0.7$ & 0.360 \\
\hline Area of right atrium, $\mathrm{cm}^{2}$ & $19 \pm 8$ & $20 \pm 6$ & 0.435 \\
\hline $\mathrm{RV}$ diameter $\mathrm{D} 2, \mathrm{~cm}$ & $3.1 \pm 0.5$ & $3.2 \pm 0.5$ & 0.525 \\
\hline E' velocity, m/s & $0.14 \pm 0.04$ & $0.15 \pm 0.04$ & 0.482 \\
\hline$A^{\prime}$ velocity, $\mathrm{m} / \mathrm{s}$ & $0.15 \pm 0.04$ & $0.22 \pm 0.22$ & 0.099 \\
\hline $\mathrm{S}$ velocity, $\mathrm{m} / \mathrm{s}$ & $0.14 \pm 0.16$ & $0.12 \pm 0.02$ & 0.455 \\
\hline $\mathrm{RV}$ ejection time, $\mathrm{ms}$ & $293 \pm 42$ & $281 \pm 42$ & 0.234 \\
\hline IVCT, ms & $76 \pm 17$ & $71 \pm 17$ & 0.241 \\
\hline IVRT, ms & $75 \pm 22$ & $74 \pm 13$ & 0.878 \\
\hline TEI index & $0.5 \pm 0.1$ & $0.5 \pm 0.1$ & 0.319 \\
\hline RV fractional area change, $\%$ & $16 \pm 4$ & $17 \pm 4$ & 0.467 \\
\hline TR max velocity, $\mathrm{m} / \mathrm{s}$ & $2.7 \pm 0.4$ & $3.0 \pm 0.5$ & 0.003 \\
\hline RVOT TVI, cm & $18 \pm 4$ & $17 \pm 4$ & 0.570 \\
\hline $\mathrm{PVmax}, \mathrm{m} / \mathrm{s}$ & $0.8 \pm 0.1$ & $0.8 \pm 0.1$ & 0.158 \\
\hline PAcT, ms & $114 \pm 30$ & $104 \pm 26$ & 0.119 \\
\hline TAPSE, $\mathrm{cm}$ & $2.2 \pm 0.6$ & $2.2 \pm 0.6$ & 0.874 \\
\hline \multicolumn{4}{|l|}{ Aortic regurgitation } \\
\hline trivial/mild/moderate & $21 / 3 / 16$ & $12 / 13 / 15$ & 0.021 \\
\hline \multicolumn{4}{|l|}{ Mitral regurgitation } \\
\hline trivial/mild/moderate & $11 / 14 / 15$ & 9/13/18 & 0.775 \\
\hline Area of mitral regurgitation, $\mathrm{cm}^{2}$ & $4.4 \pm 3.2$ & $5.0 \pm 3.2$ & 0.378 \\
\hline $\mathrm{TR}$, trivial/mild/moderate & $15 / 14 / 11$ & $7 / 23 / 10$ & 0.076 \\
\hline Area of TR, $\mathrm{cm}^{2}$ & $4.0 \pm 3.5$ & $4.0 \pm 3.0$ & 0.981 \\
\hline MVA planimetric, $\mathrm{cm}^{2}$ & $1.5 \pm 0.2$ & $1.5 \pm 0.3$ & 0.668 \\
\hline MVA PHT, $\mathrm{cm}^{2}$ & $1.5 \pm 0.2$ & $1.5 \pm 0.3$ & 0.822 \\
\hline Maximum MV gradient, $\mathrm{mm} \mathrm{Hg}$ & $12.6 \pm 4.2$ & $15.7 \pm 5.8$ & 0.010 \\
\hline Mean MV gradient, $\mathrm{mm} \mathrm{Hg}$ & $5.5 \pm 2.2$ & $7.2 \pm 3.4$ & 0.011 \\
\hline Maximum PA pressure, $\mathrm{mm} \mathrm{Hg}$ & $29.4 \pm 9.0$ & $36.8 \pm 13.0$ & 0.004 \\
\hline Mean PA pressure, $\mathrm{mm} \mathrm{Hg}$ & $19.7 \pm 6.0$ & $25.8 \pm 8.9$ & 0.001 \\
\hline
\end{tabular}

$\mathrm{E}=$ Peak early diastolic mitral inflow velocity; $\mathrm{A}=$ peak late diastolic mitral inflow velocity; $\mathrm{E}^{\prime}$ = annular early diastolic wave; $\mathrm{A}^{\prime}=$ annular late diastolic wave; $\mathrm{S}=$ systolic annular myocardial velocity; $\mathrm{RV}=$ right ventricle; $\mathrm{LV}=$ left ventricle; $\mathrm{IVCT}=$ isovolemic contraction time; IVRT $=$ isovolemic relaxation time; RVOT TVI = right ventricular outflow time-velocity integral; PVmax = pulmonary maximal velocity; PAcT = pulmonary acceleration time; $\mathrm{TR}=$ tricuspid regurgitation; TAPSE $=$ tricuspid annular plane systolic excursion; MVA = mitral valve area; $\mathrm{PHT}=$ pressure half-time; $\mathrm{MV}=$ mitral valve; $\mathrm{PA}=$ pulmonary artery. 
SF-36 scores with subscales are presented in table 1 and comparing with the control group, all subscale scores including the PCS, MCS and total SF-36 scores were significantly lower in the patient group representing a worse QoL ( $\mathrm{p}<0.05)$.

When the patient group was divided into two subgroups according to median total SF-36 score (tables 2, 3), it was found that except for hypertension, there were no significant differences among baseline clinical characteristics of patients. However, hypertension was more frequent in patients with lower total SF-36 score $(\mathrm{p}=0.011)$. Patients with lower total SF-36 score with a worse QoL had higher mean and maximum transmitral valve gradients $(\mathrm{p}=0.011$ and 0.010 , respectively), higher mean and maximum pulmonary artery pressures $(\mathrm{p}=0.001$ and 0.004 , respectively), and higher tricuspid regurgitation maximum velocity $(\mathrm{p}=$ 0.003). Aortic valve regurgitation was more severe in patients with lower total SF-36 score $(\mathrm{p}=0.021)$.

In univariate analysis, mean and maximum pulmonary artery pressure, tricuspid regurgitation maximum velocity, mean and maximum transmitral valve gradients, presence of hypertension and diabetes mellitus, body mass index, and female gender were predictive for poor QoL (table 4). In multivariable logistic regression analysis with forward stepwise method, only mean pulmonary artery pressure (OR 1.138, 95\% CI 1.049-1.234, $p=0.002$ ) was found to be an independent predictor of poor QoL in patients with mild to moderate MS (table 5).

Optimal cutoff value of mean pulmonary artery pressure to predict poor QoL was found to be $>18.64 \mathrm{~mm} \mathrm{Hg}$ with $90 \%$ sensitivity and $57.5 \%$ specificity (AUC 0.726 , 95\% CI 0.613-0.839).

\section{Discussion}

Health-related QoL is a domain of QoL assessment that is influenced by the individual's perception of his or her health status. Measurement of health-related QoL can enable physicians to understand how an illness interferes with a patient's day-to-day life, improve patient-physician communication and optimize clinical outcomes. When the valve surgery is indicated but refused by the patient, survival rates with medical treatment were $44 \pm 6 \%$ after 5 years, $32 \pm 8 \%$ after 10 years and $19 \pm 9 \%$ after 15 years [2]. However, it is a fact that QoL or quality of living is not easily defined as mere survival. The goal is not only to achieve survival, but also health, well-being and some reasonably good quality of living as well [21]. Since the success of an intervention is not anymore related to med-
Table 4. Univariate predictors of poor QoL

\begin{tabular}{llll}
\hline & $\mathrm{p}$ & OR & 95\% CI \\
\hline Mean PA pressure, mm Hg & 0.002 & 1.138 & $1.049-1.234$ \\
TR max velocity, m/s & 0.007 & 5.117 & $1.566-16.716$ \\
Maximum PA pressure, mm Hg & 0.009 & 1.074 & $1.018-1.133$ \\
Maximum MV gradient, mm Hg & 0.013 & 1.124 & $1.025-1.233$ \\
Mean MV gradient, mm Hg & 0.016 & 1.235 & $1.041-1.465$ \\
Presence of hypertension & 0.014 & 0.310 & $0.122-0.789$ \\
BMI & 0.058 & 1.084 & $0.997-1.178$ \\
Sex female & 0.087 & 3.000 & $0.854-10.541$ \\
Presence of diabetes mellitus & 0.096 & 0.248 & $0.048-1.278$ \\
\hline
\end{tabular}

All the variables from table 2 and 3 were examined and only those significant at $\mathrm{p}<0.1$ level are shown. Abbreviations as in table 3 .

Table 5. Multivariable predictors of poor QoL

\begin{tabular}{llll}
\hline & $\mathrm{p}$ & OR & $95 \% \mathrm{CI}$ \\
\hline Mean PA pressure, $\mathrm{mm} \mathrm{Hg}$ & 0.002 & 1.138 & $1.049-1.234$
\end{tabular}

Multivariable logistic regression model including all the variables from table 4. Abbreviations as in table 3.

ical progress alone, patient's QoL should also be considered $[3,4]$. Although this factor has not been thoroughly considered in surgery for several years $[4,5]$, the situation has changed and QoL after intervention has become an important parameter which determines the success. Therefore, several previous studies assessed the factors affecting QoL of patients following valvular surgery [35]. However, limited data are available regarding QoL of patients before referral to an intervention. Furthermore, hemodynamic determinants of impaired QoL has not been evaluated in this group of patients before. Questions of health-related QoL questionnaires are easy to understand, and SF-36 is a rather reliable and valid questionnaire. Hence, in this study, we aimed to expose the overlooked QoL of patients with mild to moderate MS. Not surprisingly, we found that all subscale scores including the PCS, MCS and total SF-36 scores were significantly lower in the patient group representing a worse QoL. Interestingly, when we compared the basic characteristics of patients with low and high SF-36 score by using univariate analysis, we found that patients who had accompanying hypertension, diabetes mellitus and obesity had a worse QoL. However, these factors were not indepen- 
dent predictors of poor QoL. According to the recent studies [22-24] that evaluated the QoL of patients after valve surgery, gender was found to be the most notable factor affecting the QoL, that is, being a woman was a predictor of less improvement in QoL. This could probably be secondary to more frequent social isolation and more frequent anxiety and depression. However, in this study, gender was not an independent factor affecting the QoL of patients with mild to moderate MS.

The most interesting notion of our study was that it was the first in the literature which evaluated the echocardiography-guided hemodynamic determinants of QoL via the SF-36 questionnaire in patients with mild to moderate MS during an outpatient follow-up period before surgery, and found that characteristic properties of patients had no notable effect on QoL. Furthermore, patients with lower total SF-36 score (that is, poorer QoL) had higher transmitral valve gradients and higher pulmonary artery pressures. Besides, it was shown that mean pulmonary artery pressure was the main predictor of poor QoL in patients with mild to moderate MS. Since decision to intervene in patients with MS is relatively related to the severity of these echocardiographic parameters and the QoL after an intervention has become an important factor in determining the success of that intervention, in patients, especially in those with moderate MS in whom referral to intervention is difficult, physicians can take into account of the degree of the QoL of these patients. Because in the current era of high mechanical success rate of the interventions, patients with poor QoL in association with valvular pathology can benefit from an intervention more than others with a better or preserved QoL.

There are some limitations of the current study. First of all, findings do not represent overall population with
MS and males were underrepresented in this cohort, since MS is more frequently a disease of females. Besides, other forms of MS, such as elderly patients with mitral annular calcification and associated MS were not considered at all in this study. Patients having recent problems (such as acute atrial fibrillation) were not considered in the study. Because this could have confounded QoL measures. In the study, all patients were in a stable condition for a period of time and were under control of therapeutic arrangements of the outpatient clinic. Hence, chronic rhythm problems did not seem to influence the QoL in this group. The current study did not consider patients with severe MS. However, these patients had been represented in previous studies before and after intervention; hence, much information is readily available including QoL.

\section{Conclusion}

In summary, having MS definitely brings about problems in QoL. When evaluating these patients during outpatient follow-up, we think physicians should thoroughly consider mean pulmonary artery pressure during echocardiography, as it was the main factor which affected the patients' QoL. QoL has become a necessary element when one measures the results of any intervention $[3,4,25]$. Hence, in patients with MS and worse QoL, considering that these patients can benefit from an intervention more than others who have a better preserved QoL, the degree of QoL can be a helpful parameter in determining the time of intervention, especially in patients with moderate MS in whom deciding the time of intervention with echocardiographic parameters is rather difficult.

\section{References}

1 Fieldman T: Rheumatic heart disease. Curr Opin Cardiol 1996;11:126-130.

2 Griffin BP, Topol EJ: Mannual of Cardiovascular Medicine, ed 3. Philadelphia, Lippincott Williams and Wilkins, 2009, p 214.

3 O'Boyle CA: Assessment of quality of life in surgery. Br J Surg 1992;79:395-398.

-4 Troidl H, Kusche J, Vestweber KH, Eypasch E, Koeppen L, Bouillon B: Quality of life: an important endpoint both in surgical practice and research. J Chronic Dis 1987;40:523-528.

-5 Fraser SCA: Quality of life measurement in surgical practice. Br J Surg 1993;80:163-169.

6 Miller K, Grindel CG: Coronary artery bypass surgery in women and men: preoperative profile and postoperative outcomes. Medsurg Nurs 1999;8:167-172.
Rankin SH: Differences in recovery from cardiac surgery: a profile of male and female patients. Heart Lung 1990;19:481-485.

8 King KM, Collins-Nakai RL: Short-term recovery from cardiac surgery in women: suggestions for practice. Can J Cardiol 1998;14: 1367-1371

-9 Taillefer MC, Dupuis G, Hardy JF, LeMay S: Quality of life before and after heart valve surgery is influenced by gender and type of valve. Qual Life Res 2005;14:769-778.

10 Hansen L, Winkel S, Kuhr J, Bader R, Bleese N, Riess FC: Factors influencing survival and postoperative quality of life after mitral valve reconstruction. Eur J Cardiothorac Surg 2010;37:635-644.
11 Lang RM, Bierig M, Devereux RB, Flachskampf FA, Foster E, Pellikka PA, et al: American Society of Echocardiography's Nomenclature and Standards Committee; Task Force on Chamber Quantification; American College of Cardiology Echocardiography Committee; American Heart Association; European Association of Echocardiography, European Society of Cardiology. Recommendations for chamber quantification. Eur J Echocardiogr 2006;7: 79-108.

12 Feigenbaum H: Acquired valvular heart disease; in Feigenbaum H (ed): Echocardiography, ed 5. Philadelphia, Lea and Febiger, 1994, p 239 
13 Nichol PM, Gilbert BW, Kisslo JA: Two-dimensional echocardiographic assessment of mitral stenosis. Circulation 1977;55:120-128.

- 14 Wilkins GT, Weyman AE, Abascal VM, Block PC, Palacios IF: Percutaneous balloon dilatation of the mitral valve: an analysis of echocardiographic variables related to outcome and the mechanism of dilatation. $\mathrm{Br}$ Heart J 1988;60:299-308.

$>15$ Rivera JM, Vandervoort PM, Mele D, Siu S, Morris E, Weyman AE, et al: Quantification of tricuspid regurgitation by means of the proximal flow convergence method: a clinical study. Am Heart J 1994;127:1354-1362.

- 16 Masuyama T, Kodama K, Kitabatake A, Sato $\mathrm{H}$, Nanto $\mathrm{S}$, Inoue $\mathrm{M}$ : Continuous-wave Doppler echocardiographic detection of pulmonary regurgitation and its application to noninvasive estimation of pulmonary artery pressure. Circulation 1986;74:484-492.
17 Milan A, Magnino C, Veglio F: Echocardiographic indexes for the non-invasive evaluation of pulmonary hemodynamics. J Am Soc Echocardiogr $2010 ; 23: 225-239$.

18 Galderisi M, Severino S, Cicala S, Caso P: The usefulness of pulsed tissue Doppler for the clinical assessment of right ventricular function. Ital Heart J $2002 ; 3: 241-247$.

-19 Saxena N, Rajagopalan N, Edelman K, López-Candales A: Tricuspid annular systolic velocity: a useful measurement in determining right ventricular systolic function regardless of pulmonary artery pressures. Echocardiography 2006;23:750-755.

20 Ware JE Jr, Kosinski M, Bayliss MS, McHorney CA, Rogers WH, Raczeck A: Comparison of methods for the scoring and statistical analysis of SF-36 health profile and summary measures: summary of results from the Medical Outcomes Study. Med Care 1995; 33:AS264-AS279.
21 Watts MS: Ecological health and quality of life now and forevermore. Calif Med 1970; 113:55-57.

-22 Yun KL, Sintek CF, Fletcher AD, Pfeffer TA, Kochamba GS, Mahrer PR, et al: Time related quality of life after elective cardiac operation. Ann Thorac Surg 1999;68:13141320.

23 King KM: Gender and short-term recovery from cardiac surgery. Nurs Res 2000;49:2936.

-24 Chocron S, Etievent JP, Viel JF, Dussaucy A, Clement F, Alwan K, et al: Prospective study of quality of life before and after open heart operations. Ann Thorac Surg 1996;61:153157.

25 Packa DR: Quality of life of cardiac patients: a review. J Cardiovasc Nurs 1989;3:1-11. 